\title{
LÍMITES Y UTILIDADES DEL DERECHO COMPARADO EN EL DERECHO PÚBLICO. EN PARTICULAR, EL TRATAMIENTO JURÍDICO DE LA CRISIS ECONÓMICO-FINANCIERA ${ }^{1}$
}

\author{
SUSANA DE LA SIERRA \\ Profesora titular de Derecho Administrativo \\ Universidad de Castilla-La Mancha
}

\begin{abstract}
RESUMEN
El derecho comparado es una metodología jurídica y, para algunos, una disciplina autónoma del conocimiento. Su uso en el derecho público hace aparición en un momento más tardío que en el derecho privado, pero aun así presenta idéntica legitimidad como instrumento al servicio de diversas finalidades: la introducción de nuevas soluciones jurídicas a problemas comunes o la interpretación de preceptos oscuros, entre otras. El recurso al método comparado es distinto en función del operador jurídico que acuda al mismo y, por ello, las utilidades y las finalidades de dicho método variarán según el contexto. En fin, resulta de particular interés estudiar desde una óptica epistemológica el uso directo o indirecto del derecho comparado en el marco de la crisis económica y financiera, para conocer el sentido último de las normas y de su aplicación, así como de la teoría jurídico-pública que las sostiene.
\end{abstract}

Palabras clave: Derecho público comparado; crisis económica y financiera; metodología jurídica; derecho administrativo europeo; derecho administrativo global.

\begin{abstract}
Comparative Law is a legal method and, according to some authors, an independent field of knowledge. Its use in Public law is more recent than the one in Private Law, but nonetheless it is vested with the same legitimacy as an instrument useful for various goals: the introduction of new legal solutions to common problems or the interpretation of obscure legal paragraphs, among others. The use of the comparative method differs according to each legal operator and thus the usefulness and goals of it vary depending on the context. Finally, it is of particular interest to study from an epistemological perspective the direct or indirect use of Comparative Law in the framework of the economic and financial crisis, in order to capture the final meaning of the norms and their application, as well as of the public legal theory lying behind.
\end{abstract}

1 El presente trabajo se presentó en el VI Seminario de Teoría y Método (STEM), celebrado en la Universidad de Sevilla el 27 de noviembre de 2015. Agradezco todos los comentarios que allí se realizaron, en el desarrollo de intensos y extensos debates. El trabajo se inserta, además, en el marco del Grupo de Investigación de la UCLM «Comunicación Pública: Poder, Derecho y Mensaje» (ComPublic), que ha contado con financiación Feder OP2014-2020 de Castilla-La Mancha (GI20153173).

Revista de Administración Pública

ISSN-L: 0034-7639, núm. 201, Madrid, septiembre-diciembre (2016), págs. 69-99 http://dx.doi.org/10.18042/cepc/rap.201.03 
Keywords: Public Comparative Law; Economic and financial crisis; Legal method; European Administrative Law; Global Administrative Law.

\section{SUMARIO}

I. INTRODUCCIÓN: ¿POR QUÉ UNIR DERECHO COMPARADO Y CRISIS?-II. El DERECHO COMPARADO COMO INSTRUMENTO AL SERVICIO DE LA CONSTRUCCIÓN Y DE LA INTERPRETACIÓN JURÍDICAS: 1. Qué es y para qué sirve el derecho comparado (qué no es y para qué no sirve): A) Cómo y por qué surge el derecho comparado. B) Qué evolución cabe apreciar de sus utilidades y cuáles son sus instrumentos a día de hoy. 2. Elementos metodológicos del derecho comparado con especial énfasis en la cuestión lingüústica: A) Elementos metodológicos, cultura y lengua. B) Las propuestas metodológico-comparadas más recientes-III. CRISIS, RESPUESTAS JURÍDICAS Y DERECHO COMPARADO: 1. Teoría del derecho comparado, derecho administrativo global y crisis. 2. La conceptualización de la crisis y la cristalización de los conceptos. 3. La elaboración de normas en el contexto de crisis: teoría, agentes y consecuencias: A) De teorías: Teoría Legal de los Sistemas Financieros y Derecho Comparado. B) De las formas de producción normativa y los agentes. 4. La jurisprudencia-IV. A MODO DE CONCLUSIón.

\section{INTRODUCCIÓN: ¿POR QUÉ UNIR DERECHO COMPARADO Y CRISIS?}

En el año 2002 tuvo lugar en Bruselas la Conferencia Internacional de Derecho Comparado ${ }^{2}$, que pretendía emular el espíritu del famoso congreso fundacional de esta disciplina o metodología, el celebrado en París los días 31 de julio a 4 de agosto de 1900 coincidiendo con la Exposición Universal. Tras esta definición del estado de la cuestión en 2002, la bibliografía ha ido avanzando en el análisis y profundizando en aspectos concretos. Sin embargo, en una conclusión anticipada y probablemente precipitada, cabe destacar que los grandes temas del derecho comparado, a los que a continuación me referiré, apenas han sufrido variaciones en este tiempo. Sí lo han hecho sus campos de aplicación o el contexto territorial a tener en cuenta. Como se expondrá en el repaso a la evolución histórica del derecho comparado, desde un momento inicial en el que la comparación se caracterizaba por el contraste entre ordenamientos jurídicos determinados para abordar preguntas relativas a instituciones específicas, el derecho comparado encontró acomodo después en el derecho administrativo europeo ${ }^{3}$ para más adelante hacerlo en el

2 Conferencia de Epistemología y Metodología del Derecho Comparado, Bruselas, 24 al 26 de octubre de 2002. Las ponencias están publicadas en M. VAN HoEcKe (ed.) (2004), Epistemology and Methodology of Comparative Law, Oxford/Portland Oregon: Hart.

3 Entre las numerosas obras que se han publicado al respecto me remito, por todos, a un compendio de las cuestiones esenciales de la materia contenido en la obra colectiva: Jean- 
derecho administrativo global. En el momento actual presenta interés cuál ha sido el uso del derecho comparado en uno de los datos de la realidad de mayor envergadura: la crisis económica y financiera. En diversos Estados, así como en instancias supranacionales e internacionales, se han propuesto medidas para combatir los efectos de dicha crisis. Algunas medidas se han adoptado con mayor acierto que otras y, desde el punto de vista ideológico, dichos paquetes de medidas han venido presididos por idéntico tenor ${ }^{4}$.

En este marco, la segunda parte del trabajo aborda cuáles son los elementos relevantes desde un punto de vista jurídico-comparado para el estudio de las medidas dirigidas a afrontar la crisis, así como su puesta en práctica y su control, fundamentalmente por los Tribunales Constitucionales. Cuál es, en definitiva, la agenda de investigación en este marco. Ahí encuentran aplicación las cuestiones clásicas de la metodología comparada, como la relativa al contexto, al uso del lenguaje, a los principales actores, a los problemas de los trasplantes jurídicos y, desde luego, es un ejemplo adecuado para ilustrar el fenómeno de la globalización del derecho, con los inconvenientes y las eventuales ventajas que ello comporta.

\section{El DERECHO COMPARAdO COMO INSTRUMENTO AL SERVICIO DE LA CONSTRUCCIÓN Y DE LA INTERPRETACIÓN JURÍDICAS}

\section{Qué es y para qué sirve el derecho comparado (qué no es y para qué no sirve)}

El derecho comparado se ha preguntado por sí mismo desde sus inicios como disciplina ${ }^{5}$. Podría sostenerse que nació con una crisis de identidad, algo que en cualquier caso es común a otras áreas del conocimiento, singularmente el propio derecho administrativo, que de manera

Bernard AUBY y Jacqueline DutheIL DE LA RochÈre (dirs.) (2014), Traité de droit administratif européen, Bruselas: Bruylant, $2^{\mathrm{a}}$ ed. (la primera es de 2007).

4 Sobre la dudosa constitucionalidad de algunas de estas medidas se han pronunciado ya algunos Tribunales Constitucionales y a ello me referiré en la segunda parte de este trabajo. Cabe adelantar ya, sin embargo, algunas referencias. Para el caso portugués vid. Juli Poncé SolÉ (2015), «El Estado Social y Democrático de Derecho ante la austeridad y los recortes sociales: La jurisprudencia del Tribunal Constitucional portugués y su interés para el caso español» „ReDCE, 23. Como indica este autor, aun cuando el Tribunal portugués no ha sido el único que se ha pronunciado sobre las medidas adoptadas en el contexto de crisis que han supuesto el recorte en el gasto público, sí que lo ha hecho con mayor intensidad que otros órganos equivalentes. En general sobre la crisis y su impacto en los derechos sociales, vid. Marc CARRILLO (2013), «L'impacte de la crisi sobre els drets de l'àmbit social», Revista Catalana de Dret Públic, págs. 47-72.

5 A esta cuestión me he referido con más detalle en Susana DE LA SIERRA (2004), «Una metodología para el Derecho Comparado europeo: Derecho Público Comparado y Derecho Administrativo Europeo», Cuadernos Civitas. 
reiterada se ha venido preguntando por su origen y su razón de ser. Así, en el ya citado Congreso de París de 1900 se procedió por vez primera a establecer de manera sistemática unos criterios metodológicos, el objeto y la función de este enfoque. Este momento fundacional había estado precedido, como se reconoció en el propio congreso, por autores y obras que sentaron las bases de esta aproximación. De hecho, hay quien retrotrae la "prehistoria» del comparatismo a la Edad Antigua y, en particular, a las obras de Licurgo y Solón, quienes recorrieron diversos territorios de la antigua Grecia, a fin de conocer la práctica normativa de varias comunidades y así enriquecer su propia producción legislativa. También Platón en sus Leyes abunda en la comparación para identificar las normas de la ciudad ideal, mientras que Aristóteles confrontó determinadas «Constituciones» para identificar sus elementos útiles. Sin embargo, en estos esfuerzos se encontraba ausente aquello que caracteriza la aproximación metodológico-comparada, a saber, la argumentación racional en el marco de una aproximación sistemática real o intelectual de diversos ordenamientos jurídicos o de instituciones jurídicas en un contexto superior al nacional ${ }^{6}$. En buena parte de las ocasiones se trataba de una mera yuxtaposición de textos sin abundar en el análisis preciso y esta yuxtaposición, habitual por otra parte y siendo útil a efectos informativos, no es destacable a los presentes efectos metodológicos.

Además de los antecedentes remotos y más cercanos del derecho comparado como disciplina, interesa plantearse cuál ha sido la evolución de este método, cuáles son sus líneas principales, así como sus aplicaciones. Las preguntas de investigación que cabe enunciar en este marco son las siguientes: 1) ¿Cómo y por qué surge el Derecho Comparado? ¿A qué utilidad o utilidades respondía en el momento de su surgimiento?; 2) ¿Qué evolución cabe apreciar de esas utilidades?; 3) ¿Presenta el Derecho Público límites ontológicos para la aplicación del método comparado?; 4) ¿Qué otros límites metodológicos, como la cuestión lingüística, son relevantes? A tratar de dar respuesta a estos interrogantes se dedican las líneas que siguen.

6 Sobre todo ello, cfr. Marc Ancel (1971), Utilité et méthodes du droit comparé, Neuchatel, Éditions Ides et Calendes, pág. 12. Vid. también Léontin Jean Constantinesco (1972), Traité de droit comparé, Tomo I, Introduction au droit comparé, París: LGDJ, pág. 50; Henry Walter Ehrmann (1976), Comparative Legal Cultures, Englewood Cliffs: Prentice-Hall; Walther Hug (1931/1932), «The History of comparative Law», Harvard Law Review, págs. 1027-1070. 


\section{A) Cómo y por qué surge el derecho comparado}

El derecho comparado es un tipo de análisis jurídico cuya finalidad se ha ido transformando a lo largo de la historia, ${ }^{7}$ desde el Congreso fundacional de París $^{8}$. Es un método multifuncional que tiene cabida en diversas ramas del saber ${ }^{9}$, pero que surge inicialmente en el ámbito jurídico privado. En principio, más allá del mero ejercicio intelectual, la cuestión de la finalidad de esta disciplina ha recibido diversas respuestas y entre otras las siguientes: obtener la aproximación de los ordenamientos jurídicos, ilustrar la solución de controversias rellenando lagunas que en otras áreas geográficas ya habían sido colmadas, contrastar las diversas soluciones para concluir que la comparación es imposible por cuanto las diferencias culturales impiden un análisis riguroso y serio. Todo ello ha venido determinado por las distintas etapas que ha ido atravesando la disciplina y que han estado determinadas por el contexto general, así como por los propios avances de la ciencia jurídica ${ }^{10}$.

A una primera etapa caracterizada por el optimismo y el universalismo, en la que se confiaba en la creación de unos principios jurídicos globales de general aplicación en todos los Estados, le siguió el periodo de entreguerras. Aquí ya no se trataba únicamente de identificar unos principios comunes, sino de crear un auténtico derecho mundial. Desde el punto de vista metodológico, uno de los principales escollos detectados para

7 Históricamente se ha planteado si el derecho comparado es método o ciencia autónoma, aparente paradoja que quedaría resuelta con la contundente afirmación de Alejandro NiETo (2003): "La ciencia no es a la postre sino método» (Las limitaciones del conocimiento jurídico, Madrid: Trotta). En el libro Una metodología... yo misma dedicaba atención a la distinción entre ambas perspectivas —el derecho comparado como disciplina autónoma y como método--, pero lo cierto es que dicha dualidad se reconduce a la unidad atendiendo a la posición que señalaba Alejandro NiETo y a la que me sumo. En este sentido, en este trabajo retomaré las reflexiones que en Una metodología abordaba tanto en la parte correspondiente a la disciplina como a la metodología.

8 Las actas del Congreso se publicaron en 1907 (Procès-verbaux des séances et documents, Congrès international de droit comparé tenu à Paris du 31 juillet au 4 août 1900, París, 1905 - 1907, 2 vol.) y hoy se encuentran en la Biblioteca Cujas de París. Sobre el impulsor del Congreso, Raymond SALEILLES, así como sobre el otro pilar del derecho comparado, Edouard LAMBERT, vid. Christophe JAmIN (2000), «Le vieux rêve de Saleilles et Lambert revisité. À propos du centenaire du Congrès de droit comparé à Paris», RIDC, 52, 4, págs. 733-751. Para llegar al momento fundacional del derecho comparado puesto de manifiesto en el Congreso se han de tener en cuenta algunos antecedentes, además de los referidos a la «prehistoria» de este método. Estos antecedentes son, de manera sintética, el cambio del paradigma científico tras la revolución copernicana, la Revolución Industrial y el surgimiento con la misma de una constelación más compleja de intereses, la época de la codificación jurídica y la necesidad de atender a otros referentes extranjeros para configurar las propias normas, así como, en fin, la aparición coetánea de otras ramas del saber, como la sociología jurídica o la filosofía, con las que el derecho comparado mantendrá vínculos desde sus inicios. A ello me refiero con mayor detalle en Una metodología, págs. 41-45.

9 Cfr. Harold C. GutTeridge (1949), An Introduction to the Comparative Method of Legal Study and Research, Londres, Cambridge University Press, 2a ed., pág. 10.

10 Sobre la evolución histórica me remito por todos a Marc ANCEL (1971: 18ss.). 
ello era la existencia de diferencias fundamentales entre ordenamientos jurídicos ubicados en dos bloques, familias legales o círculos jurídicos: el denominado derecho civil u ordenamientos de tradición jurídica continental frente al common law o derecho de la tradición anglosajona. Esta división ha caracterizado los rudimentos del derecho comparado desde entonces y se mantiene a día de hoy como un escollo metodológico difícil de superar, al menos según algunos teóricos que se han ocupado de la materia. La tercera etapa surge tras la Segunda Guerra Mundial. Aparecen otros referentes políticos, los de la órbita comunista, que dan lugar a una tercera familia legal, a la que se suman con timidez y sin que exista consenso en la doctrina otras familias jurídicas, como la que sistematiza el derecho de los Estados liberados de las colonias en el proceso de descolonización. Más adelante puede considerarse que la consolidación de la Comunidad Económica Europea y el surgimiento de la Unión Europea determinan una nueva etapa, en la que el derecho comparado se afana por contribuir a la armonización, a la identificación de principios comunes y, en definitiva, a la constitución de un corpus jurídico común. El derecho administrativo global sería, en el ámbito jurídico-público y a los efectos del presente trabajo, la quinta y de momento definitiva etapa.

La teoría clásica del derecho comparado, pese a la mención de los fenómenos del derecho administrativo europeo y del derecho administrativo global, se gestó y se desarrolló inicialmente en el ámbito privado. Ello es debido a varias razones, entre las que quisiera destacar ahora dos. De un lado, el propio surgimiento del derecho público tal y como lo conocemos en el Estado constitucional es más tardío que el del derecho privado. De otro lado, una aplicación práctica temprana del derecho comparado fue una rama concreta del derecho privado, el derecho internacional privado, en el que más allá de la elección de la norma de conflicto muchos elementos materiales habían de ser completados con argumentos comparados.

Con la consolidación de la hoy Unión Europea y el incremento exponencial de las normas de naturaleza jurídico-administrativa, el derecho comparado comienza a adentrarse en los contornos del denominado derecho administrativo europeo. Este concepto plurisémico remite a diversas realidades, entre las que me referiré a dos en este momento ${ }^{11}$ : las normas que rigen el funcionamiento de la Administración europea y aquellas dirigidas a los Estados miembros de carácter u objetivo relacionados con el ámbito de aplicación del derecho administrativo nacional clásico.

11 A las distintas nociones de derecho administrativo europeo me refería en Susana DE LA SiERRA (2004: 84-97). Me remito al aparato bibliográfico ahí presente y en las notas siguientes solo incorporaré las referencias posteriores. 
En el primer grupo, las normas que rigen el funcionamiento de la Administración europea, junto a los estudios iniciales relativos al derecho que resulta de aplicación a las instituciones europeas, de manera paulatina hicieron aparición obras con esfuerzos dogmáticos interesantes en la medida en que procedían a redefinir la propia noción de Administración europea, en muchas ocasiones al amparo de nuevos conceptos, como el de Unión Administrativa Europea ${ }^{12}$. En este sentido, siguiendo la estela del principio de cooperación y de la complejidad de las personificaciones públicas en Europa, así como de las relaciones entre las mismas, buena parte de estos estudios partían de análisis jurídico-comparados de construcciones, entramados y esquemas semejantes o equivalentes que pudieran arrojar luz a escala europea para abordar los nuevos fenómenos ${ }^{13}$.

En el segundo grupo, las normas dirigidas a los Estados sobre materias típicas del derecho administrativo clásico, las manifestaciones del derecho administrativo europeo son incontables ${ }^{14}$. Un ejemplo de la aproximación puede ser el derecho de la contratación pública, incluso en aquellos aspectos no afectados por las directivas y, desde luego, todo el derecho de la regulación, ámbito que guarda relación directa con la segunda parte de este trabajo.

Más adelante, como luego se expondrá, este tipo de debates se reproducirán a escala global, si bien la inexistencia a escala global de una organización a la que se haya cedido parcialmente la soberanía, con un anclaje constitucional concreto, determina que los parámetros de análisis sean necesariamente distintos.

B) Qué evolución cabe apreciar de sus utilidades y cuáles son sus instrumentos a día de hoy

Si se toma el índice del libro Epistemology and Methodology of Comparative Law citado más arriba, cabe esbozar una suerte de agenda de

12 Entre la bibliografía existente, me remitiré a Eva Nieto Garrido e Isaac Martín Delgado (2010), Derecho administrativo europeo en el Tratado de Lisboa, Madrid: Marcial Pons.

13 Cfr. a título de ejemplo Jens-Peter Schneider (2008), «Estructuras de la Unión Administrativa Europea - Observaciones introductorias», en Francisco Velasco CABALlero y Jens-Peter SCHNEIDER (coords.), La unión administrativa europea, Madrid: Marcial Pons, págs. 25-49.

14 Desde un punto de vista metodológico, por otra parte, conviene conectar esta cuestión con los debates sobre la reforma del derecho administrativo y, en concreto, con la noción de "estatalidad abierta» desarrollada por SchmidT-AssmanN. Cfr. Eberhard ScHMIDT-AssmanN (2006), «Cuestiones fundamentales sobre la reforma de la Teoría General del Derecho Administrativo. Necesidad de la innovación y presupuestos metodológicos», en Javier BARNÉs (ed.), Innovación y reforma en el Derecho Administrativo, Sevilla: Global Law Press/Editorial Derecho Global, págs. 15-132 (págs. 66-67). 
investigación general del derecho comparado desde una perspectiva contemporánea. En la misma, sin embargo, sí cabe apreciar una suerte de permanencia de las preocupaciones metodológicas clásicas.

En primer lugar, destaca el lugar que todavía ocupa en la teoría comparada la noción de familia legal y otras construcciones afines, un concepto al que me he referido más arriba al aludir al binomio derecho continental o civil law vs. common law (Cultura legal vs. tradición legal; Culturas legales y tradiciones legales; Epistemología legal y transformación de culturas legales; Árboles genealógicos para los sistemas jurídicos: hacia una aproximación comparada). El concepto de «familia legal» es una construcción teórica, una de las varias taxonomías que existen para ordenar la realidad jurídica en torno a categorías de las que forman parte ordenamientos jurídicos con características comunes y facilitar de este modo la tarea del comparatista ${ }^{15}$. Como se ha señalado anteriormente, tras la construcción tradicional en torno al binomio derecho continental o civil law vs derecho de la órbita anglosajona o common law hizo su aparición más adelante la familia del derecho socialista o comunista, así como otras categorías respecto a las que no existe consenso (el derecho de los sistemas que surgen tras la descolonización o el derecho religioso, por ejemplo). Más allá de las taxonomías consensuadas, parece claro que la comparación de cada cuestión jurídica concreta requerirá un marco teórico propio y, por lo tanto, una taxonomía singularmente diseñada para cada análisis ${ }^{16}$.

En segundo lugar, se plantean cuestiones relacionadas con la dimensión plural del derecho comparado, su relación con otras disciplinas, así como la exportabilidad del método de unas áreas jurídicas a otras (Epistemología y derecho comparado: contribuciones desde las ciencias y las ciencias sociales; Cómo hacer cosas comparables: metodología y derecho comparado - ¿Puede cambiar la metodología como para hacer frente a la multiplicidad del derecho?). Aquí ha de recordarse que el derecho comparado surge muy vinculado a disciplinas como la sociología del derecho o la filosofía, a las que ha seguido anclado. Además, la necesidad de ubicar la comparación en su contexto y de prestar atención a la cultura evoca de manera inmediata esta conexión en cierto modo natural.

En tercer lugar, se incluyen debates recurrentes en el derecho privado comparado, así como otras generales del derecho comparado, como es

15 El concepto se atribuye a René DAVID (1950), Les Grands Systèmes de Droit Contemporains, París: Dalloz. Sobre las taxonomías en derecho comparado me remito a Una metodología, cit., pp. 99-102.

16 La decadencia de las taxonomías clásicas y la aproximación a ellas desde la utilidad concreta de cada comparación se ha puesto de manifiesto en Annelise RiLEs (ed.) (2001), $R e$ thinking the Masters of Comparative Law, Oxford: Hart, pág. 2. 
la relativa al nivel de análisis ${ }^{17}$ (Derecho comparado de las obligaciones: metodología y epistemología; La codificación del derecho privado europeo; Nivel profundo del derecho comparado; Sueños y realidades del derecho privado europeo en relación con el Tratado de Niza; ¿Un lenguaje común en Europa?). En este grupo aparece tanto un interés por la macrocomparación como por la microcomparación. La macrocomparación aludiría al conjunto de normas jurídicas, instituciones de producción y aplicación de normas, conocimientos, valores y comportamientos relacionados con las normas y las instituciones, incluidos su representación física, estilística y simbólica. Este conjunto de elementos se constituye en relación a una realidad social que no ha de ser necesariamente un Estado, sino que puede abarcar un territorio superior o inferior. Por su parte, la microcomparación alude a la comparación de instituciones jurídicas concretas ${ }^{18}$.

En fin, en cuarto lugar, se apunta al derecho europeo, así como a una óptica internacional (La europeización de los sistemas legales nacionales: algunas consecuencias para el pensamiento jurídico en los países de derecho civil; Derecho comparado y la internacionalización del derecho en Europa; Derecho público en Europa: ¿atrapado entre lo nacional, lo subnacional y lo europeo?; Nuevos desafíos en la teoría jurídica internacional pública y privada: ¿cómo puede ayudar la doctrina comparatista?; La concepción política de Rawls sobre derechos y libertades: una aproximación corta de miras pero pragmática a los problemas de la armonización y de la globalización). Sorprende en el elenco el escaso tratamiento de la cuestión lingüística.

En relación con las cuestiones que han quedado ya indicadas, de la Conferencia y sus contribuciones podrían extraerse las siguientes conclusiones: 1) El concepto de "cultura» y sus distintas variantes y versiones adjetivadas continúan siendo una constante en la metodología comparada; 2) Los procesos dinámicos forman parte de la esencia metodológica del derecho comparado: así, se encuentran referencias a la europeización, la armonización, la internacionalización, la globalización; 3) La preocupación por la complejidad es asimismo un elemento presente en las alusiones a la multiplicidad o a las distintas capas del derecho que se aplican a una misma realidad; 4) Resulta necesaria la aproximación al objeto de la comparación desde disciplinas complementarias

17 Cfr. Mark van Hoecke (2002), «Deep level comparative law», EUI Working Papers, LAW $2002 / 13$

18 Cfr. Erk Volkmar Heyen (2000), Kultur und Identität in der europäischen Verwaltungsrechtsvergleichung - mit Blick auf Frankreich und Schweden, Berlín: Walter de Gruyter, pág. 17. DE LA SieRra (2004: 70-71).

Revista de Administración Pública

ISSN-L: 0034-7639, núm. 201, Madrid, septiembre-diciembre (2016), págs. 69-99 http://dx.doi.org/10.18042/cepc/rap.201.03 
al derecho, como las ciencias en general o las ciencias sociales en particular, entre las que se encuentra la economía; 5) Es habitual recurrir a ficciones o conceptos visualmente articulados, como las familias legales o los árboles genealógicos para ordenar la realidad y aproximarse a ella con este enfoque metodológico, a pesar de que la teoría contemporánea sea escéptica con estas taxonomías.

La Conferencia de Derecho Comparado se celebró en 2002 y el libro se publicó en 2004. Han transcurrido más de diez años desde entonces. Sin embargo, buena parte de las cuestiones teóricas se han mantenido en la misma línea ${ }^{19}$. Para ello puede observarse el índice de las revistas más señeras en la materia, como el International Comparative Law Quarterly, el American Journal of Comparative Law o la Revue Internationale de Droit Comparé. Los avances, en general, se están produciendo en sectores concretos o en bloques específicos, tal y como indicaba más arriba. En este contexto presenta interés estudiar si la crisis económica y financiera, que ha desatado respuestas en varios Estados, ha generado asimismo una aproximación metodológica desde el punto de vista comparado.

\section{Elementos metodológicos del derecho comparado con especial énfasis en la cuestión lingüística}

Llegados a este punto, cabe realizar un compendio de los elementos metodológicos fundamentales del derecho comparado sobre la base de cuestiones ya avanzadas, para a continuación presentar la evolución de las preocupaciones metodológicas y conectarlo así con la segunda parte de este trabajo.

\section{A) Elementos metodológicos, cultura y lengua}

Entre los elementos metodológicos clásicos en la teoría del derecho comparado destacan, en primer lugar, las taxonomías a las que se ha he-

19 Esta es asimismo la constatación que se realiza en RiLes (ed.) (2001: 2), quien afirma que existe una paradoja. Donde los comparatistas en sentido estricto están revisando las categorías tradicionales del método comparado para adaptarlas a la realidad y existe una suerte de $\mathrm{im}$ passe, dicho método comparado está encontrando una creciente aplicación en otras disciplinas (ello podría conectarse precisamente con el uso del derecho comparado en el derecho administrativo europeo y en el derecho administrativo global). Como se señala a continuación en esa obra, por otra parte, ser comparatista a día de hoy lleva innato ser un «metodólogo», dado que «ser comparatista hoy implica preocuparse por los términos adecuados, por las categorías, la escala, los métodos y los datos que se han de utilizar en la comparación». 
cho referencia (familias legales, círculos jurídicos o expresiones equivalentes), en el entendido de que se trata de un instrumento más en manos del comparatista y sabiendo asimismo que en la actualidad se subraya la necesidad de crear construcciones propias para cada comparación y no acudir a las taxonomías generales, puestas hoy en cuestión. Ello es así precisamente porque se parte de la individualidad de cada comparación, las particularidades de cada institución jurídica y la singularidad de cada ordenamiento jurídico. Así, a pesar de que las taxonomías generales resulten útiles para «ordenar» el mundo jurídico en bloques, la comparación concreta requiere detallar el contexto específico del surgimiento y aplicación de una institución jurídica. Los trasplantes jurídicos plantean idénticos problemas a los trasplantes orgánicos, de modo que la incorporación de un elemento extraño en un organismo determinado puede generar rechazo o, en general, problemas de incompatibilidad ${ }^{20}$. Para ello presenta suma importancia las nociones de «contexto» y de «cultura».

El análisis del contexto y de las culturas de origen y de recepción resulta fundamental. Para ello, desde un punto de vista metodológico conviene manejar no solamente las fuentes jurídico-administrativas, sino también el marco constitucional e incluso político. Para la auténtica aprehensión del funcionamiento de las instituciones, técnicas propias de otras ciencias sociales, como las entrevistas a actores destacados del sistema jurídico, resultan asimismo relevantes ${ }^{21}$.

En fin, la cuestión lingüística es asimismo uno de los elementos recurrentes de la comparación, tanto desde una perspectiva pasiva como desde una perspectiva activa. La necesidad de atender al amplio concepto de contexto desarrollado más arriba lleva a que resulte imprescindible tener un conocimiento lingüístico pasivo suficiente de la lengua cuyo ordenamiento se estudia, a fin de poder acceder a las particularidades últimas de dicho ordenamiento. Desde el punto de vista activo, a la hora de verter las reflexiones que parten del estudio de un ordenamiento concreto para su proyección en otro, en un conjunto de ellos o en una

20 Cfr. inter alia Alan Watson (1993), Legal Transplants: An Approach to Comparative Law, Atenas: GA, $2^{\mathrm{a}}$ ed.; Alan Watson (2000), Law Out of Context, Atenas: GA. Véase también Gunther Teubner (1998), «Legal Irritants: Good Faith in British Law or How Unifying Law Ends Up in New Divergences», The Modern Law Review, 61, págs. 11-32. La opinión no ya cautelosa sino discordante es la de Pierre LEgRAND (1997), en el sentido adelantado más arriba: "The Impossibility of "Legal Transplants" ", Maastricht Journal of European and Comparative Law, 4, págs. 111-124.

21 Sobre la cultura relevante a efectos de comparación, incluidas las referencias a la "plantilla jurídica», o bien a los sujetos que determinan la producción y aplicación jurídicas, me remito a DE LA SIERRA (2004: 67-84) [«El aspecto cultural del Derecho Administrativo y su relación con el Derecho Comparado»], así como a la bibliografía ahí referenciada. 
construcción supranacional, la elección de los términos reviste una importancia destacada. En ocasiones no existen expresiones equivalentes en la lengua de destino y se han de utilizar perífrasis o, en general, cabe acudir a las teorías de la traducción. Entre otras posibilidades puede optarse por crear macroconceptos que permitan integrar en su seno diversas categorías nacionales. Pero en cualquiera de estos supuestos se han de adoptar decisiones de estrategia lingüística ${ }^{22}$.

Un problema más reciente en relación con la lengua es la extensión de una lingua franca también en la ciencia jurídica, el inglés, debido - aunque no solo_ - a la producción creciente de escritos académicos en esta lengua por los no nativos y desde comunidades académicas que genuinamente no se han dirigido a la audiencia en inglés. La utilización del inglés viene dada así mismo por el mencionado proceso de globalización y por quienes están liderando ese proceso desde las instituciones supranacionales, en concreto Estados Unidos ${ }^{23}$. Si en las instituciones europeas y en la comunidad académica europea se utiliza de forma coloquial la expresión "euro-speak», dada la impronta de la economía en el discurso político y jurídico —como se desarrolla en otros apartados del presente trabajo - no resulta descabellado referirse al surgimiento de un «euro-eco-speak» o "eco-speak» a secas, que se ha de traducir no solo a distintas lenguas nacionales, sino que ha de encontrar acomodo en culturas jurídicas no siempre coincidentes.

\section{B) Las propuestas metodológico-comparadas más recientes}

Como avanzaba más arriba, una revisión a la bibliografía reciente arroja un resultado para la reflexión. En general, no cabe constatar una preocupación de gran envergadura por las cuestiones metodoló-

22 Sobre todo ello me remito a DE LA SIERRA (2004: 102-118), donde me adentraba también en las teorías de la traducción.

23 STEWART (2005) se ha planteado, así, si el derecho administrativo estadounidense puede considerarse un modelo para el derecho administrativo global: «U.S. Administrative Law: A Model for GAL?», $68 \mathrm{~L}$ and Contemporary Problems, 63. Sobre la influencia indirecta del derecho estadounidense en el derecho europeo se ha pronunciado José Esteve PARDo (2010), "La recepción en la Europa continental del Derecho de la regulación de la economía», en $R A P$, 183, págs. 295-307. La relevancia económica del origen jurídico la estudian, además, Rafael LA Porta, Florencio LóPEZ-DE-Silanes y Andrei SchleIFER (2007), «The Economic Consequences of Legal Origins», Working Paper 13608, NBER Working Paper Series. En línea con la creciente importancia del derecho estadounidense como fuente de inspiración para el derecho español, vid. Francisco Velasco (2015), «Die Rezeption des deutschen Verwaltungsrechts in der spanischen Rechtsordnung. Zugleich eine theoretische Darstellung der Gründe, Etappen und Probleme des unidirektionalen Rechtsvergleichs», Die Verwaltung, 48, págs. 383-404, in fine, «Die Zukunft ist weniger deutsch». 
gico-comparadas en una dimensión general del tipo de las existentes hace años. Lejos está la época de obras señeras como las de ZwEIGERT у Kӧтz ${ }^{24}$, del canadiense Patrick GLENN ${ }^{25}$, recientemente fallecido, o de iconoclastas como Pierre LEGRAND ${ }^{26}$, que continúa activo en la misma línea. Sí que hay alguna excepción de interés. Es el caso, por ejemplo, de Pier Giuseppe Monateri, con una obra prolífica y que recientemente se ha ocupado de la edición de un volumen colectivo sobre los métodos del derecho comparado, en el que aparecen nombres conocidos de esta disciplina, algunos de los cuales contribuyeron precisamente a la Conferencia sobre Metodología y Epistemología del Derecho Comparado de $2002^{27}$. Este autor es tributario de quienes subrayan -la mayoría, en realidad - la importancia de la cultura, el contexto cultural y las categorías culturales como elementos indispensables a tener en cuenta en el método comparado y en ello insiste en sus trabajos ${ }^{28}$.

Más allá de esto, existen contribuciones a materias concretas con mayor o menor pretensión de contribuir a una teoría general. Es el caso, por ejemplo, de los derechos humanos, un ámbito en el que la apelación al derecho comparado ha sido una constante en doctrina y jurispruden$\operatorname{cia}^{29}$. Y el ordenamiento jurídico español quizás resulte paradigmático

24 Konrad ZweIgerT y Hein KöTz (1996), Einführung in die Rechtsvergleichung, Tübingen, Mohr, $3^{\mathrm{a}}$ ed. De la edición en inglés existe una completa y sugerente recensión realizada por Susan Millns (1999), The International and Comparative Law Quarterly, núm. 48 (4), págs. 982-984.

25 Su obra señera es Legal Traditions of the World: Sustainable Diversity in Law, Oxford: Oxford University Press, $5^{\text {a }}$ ed., 2014.

26 Cito por todos su controvertido artículo «European Legal Systems Are Not Converging», The International and Comparative Law Quarterly, 45 (1), enero de 1996, págs. 52-81, además de su obra básica de referencia Le droit comparé (2015), París, PUF, $5^{\mathrm{a}}$ ed.

27 Pier Giuseppe Monateri (2012), Methods of Comparative Law, Elgar.

28 Cfr. a título de ejemplo, del mismo autor, "Diritto "estettica" e Soft Power. La comparazione culturale fra ordinamenti giuridici», Riv.crit.dir.priv., 2005, págs. 269-286; The Weak LawContaminations and Legal Cultures, 13 Transnational Law and Contemporary Problems, 575 (2003). Por la originalidad del enfoque puede citarse también «Il diritto comparato e Marx», en Stefano Rodotà (2004), Diritto e culture della política, Roma: Carocci, págs. 124-129.

29 Cfr. Sandra Fredman (2015), «Foreign Fads or Fashions? The Role of Comparativism in Human Rights Law», International and Comparative Law Quarterly, 64, 3, págs. 631-660. En este artículo la autora aborda el uso del derecho comparado en la interpretación y aplicación de las normas sobre derechos fundamentales abordando las críticas que se realizan al uso de este instrumento metodológico en este ámbito por ser algo equívoco, selectivo y no democrático. Apuesta por la elaboración de una teoría del discurso para de esta forma aportar argumentos comparados con solidez. Desde un punto de vista comparado, pero con una perspectiva bien diferente, presenta interés el libro colectivo de Aoifa NoLAN, Rory O'CoNNELL y Colin Harvey (eds.) (2013), Human Rights and Public Finance: Budgets and the Promotion of Economic and Social Rights, Oxford: Hart Publishing. Además de reflexiones generales sobre las obligaciones internacionales en materia de derechos humanos, se incluyen análisis comparados sobre las medidas de austeridad adoptadas por diversos Estados en época de crisis, estudiando el impacto en determinados derechos económicos y sociales, en especial respecto de algunos colectivos como los niños y las mujeres. Interesante en relación con esta cuestión es el siguiente estudio (algo escéptico), que se pregunta precisamente por los eventuales límites 
debido a la impronta del art. $10 \mathrm{CE}$, que puede considerarse una invitación no solo a la aplicación de textos internacionales para integrar los derechos constitucionales en España, sino también referentes comparados. De hecho, el Convenio Europeo de Derechos Humanos, al que se hace referencia expresa, ha dado pie a una jurisprudencia detallada por parte del Tribunal Europeo de Derechos Humanos donde el instrumento jurídico-comparado ha sido utilizado con profusión para fijar los contornos de cada derecho, de una forma también equiparable a la actuación que en este sentido ha desarrollado el Tribunal de Justicia de la Unión Europea ${ }^{30}$. Algo parecido ha sucedido también recientemente con el debate en torno al procedimiento administrativo y a la eventual codificación de su derecho regulador, tanto a nivel europeo como en algunos Estados miembros ${ }^{31}$.

Sería en cualquier caso muy osado afirmar que no ha habido contribuciones notables a la teoría del derecho comparado en los últimos años. Ciertamente las ha habido. Sin embargo, como se ha adelantado ya, se ha producido un desplazamiento de la pregunta de investigación en una doble dirección: se ha profundizado en el estudio de instituciones jurídicas concretas y, fundamentalmente, se ha avanzado en el método comparado para el derecho público.

En el ámbito público la idoneidad de los estudios comparados ha encontrado críticos acérrimos ${ }^{32}$, pero lo cierto es que la elaboración de

supraconstitucionales en los procesos de reforma constitucional, como pudiera ser —podría añadirse- el que sufrió la Constitución española en 1978 y que afectó al art. 135: Yaniv RozNAI (2013), "The Theory and Practice of "Supra-Constitutional" Limits on Constitutional Amendments», International and Comparative Law Quarterly, 62, 3, págs. 557-597.

${ }^{30}$ A todo ello me referí en el trabajo de máster (Magisterarbeit) realizado en la Universidad de Bayreuth el curso académico 1998/1999 con el título Die Europäische Menschenrechtskonvention im innerstaatlichen Recht Deutschlands und Spaniens. Positives Recht und Verfassungsrechtsprechung. En dicho trabajo empleaba las teorías de Peter HÄBERLE sobre el derecho comparado como quinto método de interpretación a continuación de los cuatro clásicos propuestos por SAVIGNY, así como su teoría del desarrollo gradual de los textos, o Textstufenparadigma, a fin de conectar el art. 10.2 CE con las disposiciones equivalentes de la Ley Fundamental de Bonn y, fundamentalmente, con la jurisprudencia constitucional al respecto. El trabajo se publicó parcialmente en la Revista Jurídica hispano-alemana (2001, pp. 22ss.) con el título «Die Europäische Menschenrechtskonvention im innerstaatlichen Recht Spaniens». Entre la bibliografía más autorizada me remito aquí a Argelia QueRALT JiménEz (2008), La interpretación de los derechos: del Tribunal de Estrasburgo al Tribunal Constitucional, Madrid: CEPC; y Lorenzo MARTín-Retortillo BaQuer (2004), La interconexión de los ordenamientos jurídicos y el sistema de fuentes del Derecho, Madrid: Civitas.

31 Véase al respecto el volumen de próxima aparición dirigido por Jean-Bernard AuBY y coordinado por Thomas Perroud (2015), Droit comparé de la procédure administrative, Bruselas: Bruylant. Véase además Javier BARnés (ed.) (2008), La transformación del Derecho Administrativo, Sevilla: Global Law Press/Editorial Derecho Global. Sobre la codificación del procedimiento administrativo en Europa, más allá de las referencias doctrinales mencionadas, se ha de partir de la obra colectiva dirigida por Oriol Mir y otros (2015), Código ReNEUAL del procedimiento administrativo de la Unión Europea, Madrid: INAP.

$32 \mathrm{El}$ caso más destacado es probablemente Pierre LEgRAND, ya citado. 
textos constitucionales en el siglo xx y el desarrollo del derecho administrativo en muchas áreas del globo han traído parejas reflexiones compa$\operatorname{radas}^{33}$. De modo que, más allá de un prurito académico, no cabe duda de que el derecho público también es apto para el análisis comparado. Puede ser que en el ámbito jurídico-público, dados sus vínculos con nociones como poder, ciudadanía o soberanía, tan enraizadas en una comprensión singular de cada comunidad política, sean necesarias unas cautelas adicionales para proceder al análisis, pero no más.

Centrándonos, por lo tanto, en el ámbito público, la evolución de los sistemas ha llevado a la creación de estructuras supranacionales a nivel regional y a nivel global. Si hace unas décadas los estudios sobre el derecho administrativo europeo conocieron su auge, en los últimos años son la globalización y la noción de derecho administrativo global quienes han adquirido protagonismo. A los efectos del presente trabajo no interesa el derecho administrativo global con carácter general: la teoría, sus perfiles, las críticas, las aplicaciones. Algo de ello se indicará en las líneas que siguen, si bien solo a los efectos instrumentales del objeto de este estudio, que es la teoría del derecho comparado. Cabe argumentar ya que en el derecho administrativo global el derecho comparado ha encontrado una nueva finalidad o nuevas finalidades que aún no han sido convenientemente exploradas y que constituyen una agenda de investigación a tener en cuenta, tal y como se expone en el siguiente apartado.

\section{CRISIS, RESPUESTAS JURÍDICAS Y DERECHO COMPARADO}

1. Teoría del derecho comparado, derecho administrativo global y crisis

La teoría del derecho comparado ha ido evolucionando desde su surgimiento como área de conocimiento o disciplina científica. Lo ha hecho, como se ha indicado en las líneas anteriores, desde una óptica eminentemente utilitarista en el sentido positivo del término, es decir, con el objeto de ofrecer respuestas y soluciones a complejos fácticos concretos. La teoría, nacida en el derecho privado, fue adentrándose también en el derecho público, constituyendo esta evolución motivo de reflexión en la doctrina. El derecho comparado en el derecho público ha encontrado acomodo, así, en contextos específicos, como los procesos

33 Además de otras referencias y de la conocida y analizada influencia del derecho administrativo francés en la gestación del español, cabe aludir a un trabajo relacionado con la recepción del derecho alemán en nuestro país, que incluye referencias jurídico-comparadas. Vid. Francisco Velasco (2015), cit. 
de reforma constitucional, los de elaboración de normas infraconstitucionales o, en general, el intercambio de experiencias de colectivos concretos en relación con la aplicación de dichas normas (por ejemplo, órganos jurisdiccionales). Más en concreto, el derecho comparado en el derecho público se ha vinculado a construcciones dogmáticas mucho más detalladas, como el derecho administrativo europeo o el derecho administrativo global (DAG).

Uno de los principales referentes del estudio sistemático del denominado derecho administrativo global ha sido el grupo que con el mismo nombre se constituyó en la New York University en torno a Richard B. STEWART y que desarrolló vínculos con otros contextos geográficos, como se pone de manifiesto en los seminarios desarrollados en Viterbo ${ }^{34}$. Su artículo fundacional data de $2005^{35}$, es decir, de la antesala de la crisis económica y financiera. Sin embargo, algunos de los integrantes de este grupo en sentido amplio relativamente informal habían ya anticipado lo que serían las bases de esta nueva aproximación metodológica. Es el caso destacado de Sabino CASSESE y de su Escuela, quienes se han mostrado particularmente activos en este ámbito ${ }^{36}$. En 1998, a raíz de la puesta en funcionamiento del euro, CASSESE reflexiona sobre la pérdida de «estatalidad» ante la cesión de soberanía en el ámbito monetario ${ }^{37}$. Retomando su ya consolidada teoría sobre las bases del derecho administrativo, repasa el surgimiento y la evolución del mismo, y concluye con una reflexión sobre el Estado capturado por la economía, que resulta singularmente pertinente en el momento actual. En 2002 profundiza

34 Mercè Darnaculleta da cuenta del surgimiento paralelo de propuestas equivalentes, si bien que con parámetros culturales distintos: el mencionado derecho administrativo global o Global Administrative Law y el derecho administrativo internacional o Internationales Verwaltungsrecht en torno a la figura de Eberhard Schmidt-Assmann. Cfr. "El Derecho Administrativo Global: Un nuevo concepto clave del Derecho Administrativo», Revista de Administración Pública, 199, págs. 11-50. En relación con la bibliografía general sobre el derecho administrativo global, me remito a dicho artículo así como a la información bibliográfica contenida en http://www.irpa.eu/wp-content/uploads/2011/06/BibliografiaGAL-aggiornata. pdf, e incluiré aquí las referencias que resulten más pertinentes para el desarrollo del discurso. Sobre los seminarios de Viterbo, remito a la información publicada en http://www.irpa. eu/category/gal-section/galeminors. Las referencias a los sitios de internet citados aquí están actualizadas a 1 de noviembre de 2016.

35 Benedict Kingsbury, Nico Krisch y Richard B. Stewart (2004), «The Emergence of Global Administrative Law», Working Paper, Institute for International Law and Justice, New York University School of Law, Working Paper 2004/1 y publicado también en Law and Contemporary Problems, 68, 2005, págs. 15 - 61. Disponible en http://www.iilj.org/publications/the-emergence-oj-global-administrative-law-3/. Las citas en el presente trabajo lo son al trabajo original inglés en su publicación en Law and Contemporary Problems.

36 Cfr. los trabajos desarrollados bajo el paraguas institucional del Istituto di ricerche sulla pubblica amministrazione, con una remisión específica ahora al proyecto Global Administrative Law: http://www.irpa.eu/.

37 Sabino CASSESE (1998), Lo Stato introvabile, Roma: Donzelli. 
en la cuestión materia de este trabajo en La crisi dello Stato ${ }^{38}$, para el año siguiente publicar Lo spazio giuridico globale ${ }^{39}$.

El proyecto «Derecho Administrativo Global» se presenta como una agenda de investigación con una óptica metodológica determinada. Implicaría una suerte de «militancia», por recuperar aquí la expresión contundente y acertada que empleó Mercè DARNACUlLETA en la exposición oral de su trabajo en el IV Seminario de Teoría y Método celebrado en Barcelona el 28 de noviembre de $2014^{40}$. En el texto escrito, la autora alude a la noción de compromiso de los administrativistas imbuidos de anhelos globalizantes para describir la implicación personal de quienes abordan el estudio de esta materia, como un concepto instrumental -O aspiracional, podría sugerirse - en torno al cual articular un sistema de garantías frente a la autoridad equivalentes a las existentes en derecho interno ${ }^{41}$.

Desde el punto de vista de la metodología jurídico-comparada, interesa destacar del DAG los siguientes aspectos. En primer lugar, se ha de subrayar el hecho de que hay un término de compleja traducción al castellano, que es utilizado por los autores como leitmotiv o concepto fuerza en torno al cual articular la agenda de investigación. Es el concepto de accountability, que precisamente suele ponerse como ejemplo en ejercicios de metodología jurídico-comparada para mostrar las dificultades lingüísticas y conceptuales en la importación de categorías jurídicas de otros contextos ${ }^{42}$. Este concepto remite a la necesidad de controlar la actuación de los poderes públicos a fin de garantizar los derechos ciudadanos. Como señala DARnAculleta, en definitiva, el DAG - en conexión con la noción de accountability - es «un proyecto normativo que pretende que el ejercicio de autoridad y de poder público a nivel supranacional se dote de las mismas garantías que son exigibles a dicho poder en el ámbito nacional respectivo». El aspecto comparado adquiere una nueva dimensión. No se trata únicamente de realizar una comparación de tipo horizontal, entre Estados, sino también de implicar la verticalidad en este ejercicio.

Además de la noción transversal de accountability, el proyecto DAG propone identificar una noción de Administración a nivel global a tra-

\footnotetext{
38 Roma-Bari: Laterza.

39 Roma-Bari: Laterza. Más adelante interesa, ya con traducción al castellano, Sabino CASSESE (2010), El Derecho Global. Justicia y democracia más allá del Estado, Sevilla: Global Law Press/Editorial Derecho Global.

40 Mercé Darnaculleta (2016), cit.

41 Cfr. pp. 8 y 28 del texto original presentado al STEM.

42 Ibid., p. 6 y bibliografía ahí especificada. Una referencia temprana es asimismo Carol Harlow (2002), Accountability in the European Union, Oxford: Oxford University Press.
} 
vés de la construcción teórica de un «espacio administrativo global» 43 partiendo de los sujetos que lo configuran ${ }^{44}$. Una vez identificado este espacio habría que determinar el ámbito de aplicación exacto y las fuentes del derecho administrativo global, circunstancia que remite a los estudios sobre las bases constitucionales en derecho administrativo nacional, pero también europeo. La agenda de investigación se pregunta también por la legitimidad, los mecanismos de transparencia, así como por el equilibrio necesario entre la accountability o sistema de garantías y la necesaria eficacia de la acción de los poderes públicos. En fin, se sugiere que todo lo anterior se ha de situar en un marco de teoría política en el que encajen las soluciones jurídicas.

El derecho comparado resulta aquí de una utilidad evidente a la hora de integrar los conceptos que constituyen la agenda de investigación, conceptos como Administración o fuentes del DAG, entre otros. Los desafíos metodológicos son los clásicos ya expuestos, con algún añadido. Así, en la medida en que el DAG surge en contextos académicos concretos, vinculados a determinadas lenguas (fundamentalmente inglés, también alemán) y a tradiciones jurídicas concretas, cabe pensar que lengua y tradiciones componen una «mochila» terminológica y conceptual de la que el comparatista ha de ser consciente en su esfuerzo constructor y dogmático. El comparatismo, una vez más, se encuentra rodeado de cautelas. En este sentido, sí cabe señalar que KIngsburg, KIRsch y STEWART apuntan a la necesidad de reflexionar sobre las categorías jurídicas de un modo plural. Así, al afrontar la necesidad de definir la noción de «derecho administrativo» apelan a la tradición europea (entiendo que sumándose en realidad a la estela francesa y a sus herederos, fundamentalmente), en la medida en que indican que las definiciones del derecho administrativo en Europa son taxonómicas y no normativas, proponiendo a continuación que la definición de derecho administrativo global ha de basarse asimismo en taxonomías. Y una taxonomía de estas características parece que precisarme habrá de basarse en un análisis comparado de las concepciones nacionales.

El derecho administrativo global, por otra parte, si bien pretende tener una amplitud objetiva y subjetiva, lo cierto es que encuentra como

43 Puede sostenerse que la noción contemporánea de espacio en el análisis jurídico ha dejado lugar al concepto de mercado, algo que mejor define la actitud de quienes buscan «las mejores normas» en un complejo concreto de problemas. En este sentido puede entenderse lo afirmado por Francisco Velasco, (2005: 5).

44 Este espacio sería ciertamente plural y compuesto por entidades típicamente públicas, como los propios Estados, además de sujetos privados, como las ONG o entes de naturaleza mixta o sui generis, como son los organismos internacionales de regulación. Cfr. KINGSBURG, KiRSCH y STEWART (2004: 18). 
ámbito de aplicación esencial el económico. Así, Kingsburg, Kirsch y STEWART ponen de manifiesto que algunos de los regímenes regulatorios más densos han surgido en el ámbito económico y, a mayor abundamiento, cabe señalar que los estudios sectoriales sobre este particular en general se centran en las instituciones de naturaleza económica y los efectos de sus decisiones, toda vez que el poder económico es, de lejos, el mejor organizado y el que cuenta con mecanismos más ambiciosos para el desarrollo de sus principios ${ }^{45}$.

Teniendo en cuenta estos antecedentes, cabía pensar que la crisis económica y financiera desatada el año 2007 en Estados Unidos y «contagiada» a Europa en 2008 era un buen ejemplo para abordar las dinámicas del derecho comparado, dado que la cuestión incluye elementos que la hacen óptima para un análisis de estas características: 1) El punto de partida es común a muchos Estados, aun cuando los perfiles concretos de la crisis puedan diferir en cada uno de los casos en mayor o menor grado; 2) La crisis es un hecho internacional, debido a su propia dinámica; 3) En todos los Estados se han ofrecido soluciones políticas y jurídicas que han comportado resultados diversos; 4) Los Estados proceden de diversas tradiciones jurídicas, de ahí que presente interés discernir cuáles han sido las medidas y si dicha tradición ha pesado o no en su adopción; 5) Algunos de estos Estados forman parte de estructuras políticas y jurídicas supranacionales, en las que se han establecido directrices para controlar el proceso de respuesta frente a la crisis. Con lo anterior cabe concluir que, en efecto, se trata de una cuestión que presenta interés para el derecho comparado, pero que todavía no ha sido objeto de reflexión metodológica suficiente.

La anterior afirmación, lógicamente, ha de ser matizada de forma parcial. Así, si bien es cierto que no existe una aproximación metodológico-comparada completa a la crisis, sí que existen estudios que pueden tomarse como punto de partida en esta construcción. De un lado, todos los materiales dogmáticos relacionados con el DAG resultan pertinentes. De otro, los estudios que abordan, de manera comparada o no, aspectos de la crisis o de sus detonantes serán en todo caso elementos indispensables para el análisis ${ }^{46}$.

45 A estas cuestiones con carácter general nos referimos en Juana Morcillo MoRENo y Susana DE LA SIERRA Morón (2011), «From national Administrative Law to globalisation: economic crisis, governance and regulated self-regulation. Spain», en European Review of Public Law, 23, págs. 381-407.

46 Vid. ad ex Antonio Arroyo GIL e Isabel M. Giménez Sánchez (2013), «La incorporación constitucional de la cláusula de estabilidad presupuestaria en perspectiva comparada: Alemania, Italia y Francia», REDC, 98, págs. 149-188; Paula Fernández-Wulf Barreiro (2012), "Límites constitucionales al gasto público: Suecia, Reino Unido, Suiza, Chile y Alemania», Fedea, págs. 1-34. 


\section{La conceptualización de la crisis y la cristalización de los conceptos}

Más arriba se aludía a la cuestión lingüística en el derecho comparado, apuntando al surgimiento de una neolengua, una suerte de euro-ecospeak. Cabe importar aquí toda la teoría sobre la adopción de términos procedentes de otros ordenamientos jurídicos y las consecuencias que ello comporta, en la medida en que con el término se incorpore también - o no- la correspondiente dogmática, o bien que la misma se adopte de manera equivocada o, simplemente, distinta. Este discurso resulta asimismo de aplicación a la incorporación en el derecho de conceptos procedentes de otras disciplinas o simplemente de elementos extraídos de la realidad que reciben una nueva pátina.

La crisis ha sido ampliamente conceptualizada en el ámbito económico, como es lógico, y a estas alturas un ciudadano medianamente leído tiene una opinión formada sobre las teorías y contrateorías relativas a las causas remotas e inmediatas de la misma, así como sobre las recetas que grosso modo se han ido adoptando a nivel nacional e internacional, bajo los auspicios en cualquier caso de instituciones internacionales. El concepto de crisis que se encuentra en la génesis de la producción normativa es, por tanto, un concepto económico y las respuestas a dicha situación han venido dadas, por lo general, siguiendo la línea de teorías económicas muy concretas. Es cierto que se han producido vaivenes: así, de una primera fase en la que las respuestas lo fueron de tipo keyneasiano, con inversiones, se pasó a la segunda fase bajo el eslogan de "austeridad», que ha generado reacciones políticas y sociales, pero también jurídicas ${ }^{47}$. Desde un punto de vista comparado, interesa destacar que eso ha sido así en un buen número de Estados. Si bien es cierto que en los últimos meses se ha producido un cierto viraje respecto de la dirección hasta entonces adoptada, debido a varias causas, las medidas que hasta la fecha se han adoptado para abordar los efectos de la crisis se sitúan en el entorno conceptual mencionado.

47 Un análisis temprano de las medidas de carácter jurídico-público que se adoptaron en España y otros Estados es el realizado por Antonio EMBID IRUJo en varios trabajos, cuyas líneas fundamentales sintetizó en la ponencia presentada en el VI Congreso de la Asociación Española de Profesores de Derecho Administrativo, celebrado en Palma de Mallorca los días 11 y 12 de febrero de 2011 con el título «El Derecho Público de la crisis económica», disponible en el sitio de internet de la asociación: http://www.aepda.es/EscaparateFamilia.aspx?id=71-Actividades-Congresos-de-la-AEPDA.aspx. En el mismo lugar pueden encontrarse ponencias y comunicaciones que abordan el proceso desde perspectivas más concretas. Del mismo autor antes citado ha de hacerse referencia igualmente a La constitucionalización de la crisis económica, Madrid: Iustel, 2012. También cabe remitirse, por todos, al volumen monográfico de Documentación Administrativa, nueva época, 1, enero-diciembre 2014. En este volumen, también de EMBID IRUJo, apuntando a la cuestión lingüística, vid. «Norma, Economía y Lenguaje en el derecho de la crisis económica. El control judicial de la actividad administrativa en la economía. Algunas reflexiones». 
Al ser la crisis una crisis global, caracterizada por las relaciones intrínsecas de los mercados financieros, los efectos de la crisis han sido sistémicos. Cabe plantearse, por tanto, si las respuestas también lo han sido. La globalidad del fenómeno ha tenido diversas consecuencias interesantes desde el punto de vista metodológico: se ha producido la integración de conceptos de manera habitualmente acrítica en las instituciones (la propia noción de austeridad, por ejemplo, o el término pretendidamente técnico de «reformas») ${ }^{48}$; ha tenido lugar una cierta mutación constitucional encubierta $-\mathrm{O}$ no- en la medida en que determinados principios, como el de eficiencia, han pasado a ocupar un lugar preeminente en la interpretación y en la aplicación del derecho; en general, los conceptos económicos han pasado a vertebrar el sistema jurídico; y todo ello ha redundado en un papel protagonista de las personas e instituciones con sello económico en detrimento de otros sujetos. Así, los «técnicos» han pasado a dominar el sistema.

Esta concepción de la crisis, de los desencadenantes y de los conceptos esenciales ha condicionado, por tanto, la generación de las respuestas normativas. Es, probablemente, el contexto en el que hay que situar cualquier análisis comparado sobre la materia. La crisis ha sido un detonante para una nueva comprensión del derecho. Ha situado la economía en el centro del debate público y jurídico, con una serie de consecuencias, de modo que interesa acudir al derecho comparado para comprender todo el proceso y esas consecuencias.

\section{La elaboración de normas en el contexto de crisis: teoría, agentes y consecuencias}

En el epígrafe anterior se han apuntado ya algunas cuestiones relacionadas con la elaboración de normas en el contexto de la crisis, en la medida en que dependen de esa precomprensión que se elabore sobre sus contornos y su esencia. Me detendré en alguno de estos elementos,

48 Mario SAVINo ha analizado las reformas de la Administración Pública en Italia bajo el prisma de las consecuencias para la noción de Estado. Cfr. "Le riforme amministrative: la parabola della modernizzazione dello Stato", Rivista trimestrale di diritto pubblico, abril-junio 2015, núm. 2, págs. 641-690. En el último apartado este autor se pregunta por el método, los factores y la ideología de las reformas, y entre ellos destaca, en primer lugar, la óptica de las finanzas públicas, singularmente en los últimos años, indicando que las mismas se encuentran en realidad en una "crisis permanente» y remite aquí a la obra de David OsBorne y Peter HutCHInson (2004), The Price of Government: Getting the Results We Need in an Age of Permanent Fiscal Crisis, Nueva York: Basic Books. Singularmente relevante desde el punto de vista comparado es la contribución de Giulio NAPOLITANO en el mismo número bajo el título «Le riforme amministrative in Europa all'inizio del ventunesimo secolo», págs. 611-640, desde la óptica también del impacto de la crisis económica y financiera en este ámbito. 
en la medida en que presenten interés desde el punto de vista comparado, pero con carácter previo realizaré unas consideraciones de carácter general sobre el marco teórico de la crisis y de su «ecosistema» más inmediato: los mercados financieros.

\section{A) De teorías: teoría legal de los sistemas financieros y derecho comparado}

Existen algunas propuestas dirigidas a elaborar una teoría legal de los sistemas financieros, asumiendo que las nociones de inestabilidad y crisis han sido y son consustanciales a dichos sistemas ${ }^{49}$. A ellas he acudido para tratar de identificar un marco teórico del análisis. Si bien los efectos jurídico-administrativos de la crisis son más amplios y no se circunscriben única y exclusivamente a los mercados financieros, este ámbito es sin duda el punto de partida en la medida en que la crisis económica tuvo como detonantes agitaciones en estos mer$\operatorname{cados}^{50}$. Por esa razón, y como elemento inicial del discurso, puede pasarse revista de modo somero a dicha teoría legal de los sistemas financieros, para a continuación plantearse el papel del derecho comparado en la misma.

49 Cfr. Katharina Pistor (2013), «A Legal Theory of Finance», Columbia Law School, Public Law \& Legal Theory Working Paper Group, Paper number 13-348, 9 de mayo de 2013, passim. Vid. también Guillermo DE LA DEHESA (2009), La primera gran crisis financiera del siglo XXI, Madrid: Alianza Editorial. El autor señala que existen crisis desde que se tiene constancia documental histórica y que el comportamiento, la confianza, de los actores económicos ha sido siempre vital en este marco. Es una tesis general en todo el libro, que aparece expresada ad ex en las págs. 12 y 13.

50 En el ámbito financiero, más allá de consideraciones generales, interesa aquí apuntar a las dinámicas de armonización, en las que el derecho comparado desempeña un papel relevante, como las que se han dado en el marco del Comité de Basilea. Véase al respecto Rosario LeÑero Bohórquez (2015), «El Comité de Basilea como poder público global para la armonización normativa bancaria. Implicaciones para el Derecho Público», en María Amparo SALVAdoR ARMENDÁRIZ (dir.), Regulación bancaria: Transformaciones y Estado de Derecho, Cizur Menor: Thomson Reuters-Aranzadi, págs. 184-251. En este trabajo LEÑERo se remite precisamente al marco teórico ofrecido por el DAG y por el Internationales Verwaltungsrecht, apuntando a las diferencias entre ambas nociones, pero fundamentalmente a la distinta aproximación respecto de la noción de legalidad como criterio de legitimación del poder público. La autora concluye que, dadas estas diferencias y analizando la deriva de la regulación financiera a nivel global, «el Derecho público de raíz anglosajona [...] [se encontraría] en mejor posición para ofrecerse como modelo para una juridificación de la globalización financiera». En este sentido, el método comparado aparecería de nuevo como herramienta para la configuración de instrumentos globales de regulación. De lo anterior se deduce, además, que con ello se plantea que la legitimidad en general de la actuación de las instancias públicas requiere de un nuevo tratamiento, en línea con algunas propuestas doctrinales. Sobre la legitimación en el marco global, véanse las contribuciones al apartado «El debate sobre la legitimación en la era global», en Mercè Darnaculleta Gardella, José Esteve Pardo e Indra Spiecker Gen. Döhmann (eds.) (2016), Estrategias del Derecho ante la incertidumbre y la globalización, Madrid: Marcial Pons. 
La teoría legal de las finanzas o de los sistemas financieros (Legal Theory of Finance/LTF) parte de la siguiente premisa. La incertidumbre $^{51}$, la volatilidad [de la liquidez] y la inestabilidad son elementos consustanciales a los mercados financieros y, por tanto, han de encontrar acomodo en la regulación ${ }^{52}$. Son elementos necesarios y no contingentes, de modo que el sistema jurídico y las instituciones públicas han de contar con ello a la hora de diseñar estrategias. Además, el dinamismo caracteriza el funcionamiento de estos mercados, circunstancia que justifica que la teoría legal diseñada para ofrecer un marco que rija dicho funcionamiento la haya de tener en cuenta. De hecho, la propia noción de crisis es inherente a las dinámicas de estos mercados, en la medida en que se han venido produciendo y se producen de manera cíclica. La LTF se presenta como un proceso inductivo que parte de un dato real, como son dichos mercados, para a continuación ofrecer respuestas normativas. Desde un punto de vista metodológico se insiste en que la realidad de la que surge la inducción es transnacional y, por lo tanto, los instrumentos que se diseñen no pueden encontrarse en conflicto con las normas de los diversos países ${ }^{53}$. Si este es el dato que interesa a los presentes efectos, dado que evoca la necesidad de ofrecer una agenda de metodología jurídico-comparada en la elaboración de las normas, antes de continuar cabe mencionar sucintamente algunos elementos que se identifican en la LTF para su configuración y que son los siguientes.

La LTF parte de la existencia de una jerarquía y se propone su redefinición: los sistemas financieros serían esencialmente jerárquicos y el derecho habría de tener en cuenta dicha jerarquía. Sin embargo, la jerarquía no sería una jerarquía al uso. Así, la naturaleza jurídica vinculante de las obligaciones legales y contractuales sería inversamente proporcional a la posición en la jerarquía de las posiciones financieras. Es decir, cuanto mayor sea el compromiso jurídico — por ejemplo, la deuda de un Estado frente a una obligación contractual de poca envergadura que haya asumido un particular- mayor será la necesidad de flexibilizar el incumplimiento. Esta afirmación se sustenta en la necesidad de garantizar la flexibilidad de las bases jurídicas fundamentales de funcionamiento de los mercados financieros, a fin de que los poderes

51 Con carácter general me remito in toto sobre este concepto a Darnaculleta Gardella, Esteve Pardo y Spiecker Gen. Döhmann (eds.) (2016).

52 Además de esta premisa general del trabajo de Pistor, Katharina (2013), véase Pistor, Katharina/Milhaupt, Curtis (2008): Law and Capitalism: What Corporate Crisis Reveal about Legal Systems and Economic Development in the World, Chicago, Chicago University Press. Los autores promueven el estudio de las dinámicas del sistema capitalista y, en particular, de determinadas prácticas empresariales, sosteniendo su análisis con un estudio comparado de seis países.

53 Cfr. Pistor, Katharina (2013), cit.: pág. 2. 
públicos puedan reaccionar atendiendo a las características de inestabilidad, volatilidad e incertidumbre mencionadas más arriba ${ }^{54}$. Apoyada en esta suerte de rebeldía jurídica, la autora viene a sugerir que de esta forma podrían relativizarse las exigencias de austeridad que han sido defendidas desde algunas instancias ${ }^{55}$.

La definición de los distintos actores en la jerarquía determinaría su posición en tiempos de crisis, sin olvidar que buena parte de dichos actores en los mercados son los propios Estados, que a su vez contribuyen a la elaboración de las normas que determinan la configuración y la salida de dicha crisis. Así, y en relación con los Estados, indica PISTOR que la posición jerárquica de los mismos depende de contingencias históricas ${ }^{56}$, algo no fácilmente asible, pero que tiene consecuencias importantes, como se ha señalado. Se ha producido un desplazamiento del centro regulatorio y nuevos actores, como los bancos centrales, adquieren funciones importantes en la aplicación de dichas normas.

Los datos anteriores han de ser tenidos en cuenta para la elaboración de la LTF, que no deja de ser una teoría vinculada a otras formuladas con carácter previo y que abundan en la relación entre derecho y economía, pero de las que PISTOR se separa. La aportación fundamental de la LTF es el intento omnicomprensivo de teorizar la globalización con el ejemplo de los mercados financieros caracterizados por las notas de inestabilidad, incertidumbre y volatilidad, de asumir la crisis como algo necesario y no contingente a tener en cuenta en la regulación y a determinar, en definitiva, en quién se deposita la confianza. Gestionar la incertidumbre y la inestabilidad deviene el foco principal del análisis, mientras que cuestiones como la discrecionalidad y la accountability, al igual que en las aportaciones del DAG, se erigen en conceptos clave. En todo ello, el enfoque comparado atraviesa una parte importante de los planteamientos.

B) De las formas de producción normativa y los agentes

En el contexto que se ha expuesto, cabe ya adentrarse en la cuestión de las formas de producción normativa para afrontar los efectos de la crisis económica y financiera. Se ha de señalar que los procesos de producción normativa en el contexto de la crisis no apelan directamente a

\footnotetext{
54 PISTOR afirma textualmente que «[i]n the event of crisis, however, legal constraints are more often honoured in their breach than in their enforcement» (2013: 33).

55 Ibid., p. 16.

56 Ibid., p. 19.
} 
referentes comparados. Cosa distinta, sin embargo, es que se produzcan ciertas similitudes en la forma de producir normas en este contexto, o bien que la asimilación de otras tradiciones jurídicas opere en realidad mediante la asunción de conceptos, principios o instituciones jurídicas a través de normas emanadas de organismos internacionales y elaboradas a imagen de ordenamientos jurídicos concretos.

En primer lugar se ha de identificar el espacio que determina la elaboración de las normas y dicho espacio es el mercado, en el sentido ya avanzado $^{57}$. Las soluciones que cabe adoptar vienen determinadas por ese prisma, pretiriendo en muchas ocasiones los principios y los objetivos ajenos a la noción de mercado.

En segundo lugar cabe preguntarse por las normas fundamentales, las que constituyen el marco jurídico esencial de las medidas que vayan a adoptarse. Dichas normas son las procedentes de organismos internacionales, en buena medida, con los problemas que ello plantea y a los que no voy a referirme con detalle ahora, por cuanto en realidad se escapan del enfoque concreto de este trabajo. En este sentido me remitiría aquí a la noción de las bases constitucionales del DAG y/o del Internationales Verwaltungsrecht. Y en la agenda comparada interesa identificar el eventual cambio de jerarquía normativa interna — si es que tal jerarquía interna es admitida- entre principios constitucionales, pretiriendo algunos de ellos (notoriamente los de carácter social) frente a aquellos de tinte económico. Conceptos como eficiencia y sostenibilidad han adquirido aquí una relevancia singular y se han erigido en criterios de referencia de todo el ordenamiento jurídico. Ello presenta importancia toda vez que el derecho administrativo de un contexto nacional concreto se encuentra directamente relacionado con el tipo de sociedad democrática en la que se aplica y para su comprensión se ha de partir de una visión concreta de la teoría política que abraza dicha sociedad ${ }^{58}$.

Sobre la base de lo anterior, en tercer lugar, se ha de hacer referencia a las reformas expresas o por mutación constitucional de las Cartas Magnas de los Estados a resultas de la crisis ${ }^{59}$. Las reformas más evidentes son aquellas debidas al cumplimiento de obligaciones europeas, reformas que, sin embargo, difieren parcialmente en sus contornos ${ }^{60}$. En este

57 Cfr. nota 43.

58 En este sentido cfr. la visión reiterada de Paul CRAIG y, en concreto, la idea tal y como está reproducida se encuentra en Administrative Law, Thomson/Sweet Maxwell, $5^{\mathrm{a}}$ ed., 2003, pág. 3.

59 Además de las referencias al caso español que se citan en otros lugares del presente aparato de notas, véase para Italia Gabriele Botтino (2014), «Il nuovo articolo 97 della Costituzione», Rivista trimestrale di diritto pubblico, 3, págs. 691-719. Véase también Simone LuCATTINI (2014), «Lo stato debitore», Rivista trimestrale di diritto pubblico, 4, págs. 976-1029.

60 Véase por todos el completo análisis de Jorge García-AndRade Gómez (2012), «La reforma del artículo 135 de la Constitución Española», Revista de Administración Pública, 187, 
apartado interesa también abordar la jurisprudencia constitucional sobre la materia, aspecto —en general el de la jurisprudencia- al que se dedica el último de los epígrafes de este bloque, al que me remito ahora.

Por debajo de la Constitución, en cuarto lugar, presenta interés el recurso a instrumentos jurídicos distintos de la ley y, en general, a la normativa de urgencia y/o el uso de normas procedentes del Gobierno para situaciones excepcionales ${ }^{61}$. Además, continuando con el nivel infraconstitucional, cabe señalar que existen ámbitos de la realidad que han resultado singularmente afectados por el nuevo entorno jurídico derivado de las exigencias de estabilidad presupuestaria. Es el caso, por ejemplo, de diversas manifestaciones del Estado de bienestar ${ }^{62}$ o del régimen jurídico local, tanto en España como en otros Estados ${ }^{63}$.

Las exposiciones de motivos de las normas no contienen alusiones a otros modelos, ni tampoco en la aplicación de dichas normas se recogen reflexiones comparadas que ilustren la interpretación. Sin embargo, no cabe ocultar la relevancia multi e internacional de la materia ya mencionada y, desde un punto de vista metodológico, se ha evidenciar que estas

págs. 31-66

61 En relación con esta materia, vid. Marc CARRILlo (2014), «Reforma constitucional, finanzas públicas y una consecuencia: el abuso del Decreto-Ley y la vulneración de derechos sociales», Gaceta sindical: reflexión y debate, 23, págs. 161-180, así como, ya fuera de nuestro país, Margit CонN (2015), «Non-Statutory Executive Powers: Assessing Global Constitutionalism in a Structural-Institutional Context», International and Comparative Law Quarterly, 64, 1, págs. 65-102. La autora desarrolla elementos para un análisis comparado de esta cuestión y considera que se ha producido una cierta convergencia funcional entre ordenamientos jurídicos en esta materia. En general, sobre el uso del Decreto-Ley en España desde la aprobación de la Constitución, vid. Luis Martín Rebollo (2015), «Uso y abuso del Decreto-Ley (un análisis empírico)», Revista Española de Derecho Administrativo, 274, pp. 23-92. Un trabajo más antiguo, pero que no por ello pierde su actualidad, es Andrés Borx PaLop (2004), Las convalidaciones legislativas, Madrid: Iustel. En relación con esta cuestión véase también Mario PeRINI (2013), «El Presidente della Repubblica in tempo di crisi», Rivista trimestrale di diritto pubblico, 1, págs. 99-140, ya que el autor sitúa la cuestión precisa de los poderes del presidente de la República en el tema más amplio de los instrumentos previstos en el ordenamiento jurídico para las situaciones de emergencia o los tiempos de crisis. En fin, me remito también a Annalisa GHIRIBELli (2011), Decretazione d'urgenza e qualità della produzione normativa, Milán: Giuffrè.

${ }^{62}$ Cfr. ad ex José Luis PIÑar MAÑas (dir.) (2013), Crisis económica y crisis del Estado de Bienestar: el papel del Derecho Administrativo, Actas del XIX Congreso Ítalo-Español de Profesores de Derecho Administrativo, Universidad San Pablo-CEU, Madrid, 18 a 20 de octubre de 2012, Madrid, Reus. En otras coordenadas y en general, sobre esta materia, vid. Giulio NaPOLITANO (2012), Uscire dalla crisi. Politiche pubbliche e trasformazioni istituzionali, Bolonia: Il Mulino; ídem (2012), "From the Financial to the Sovereign Debt Crisis: New Trends in Public Law», Rivista trimestrale di diritto pubblico, 1, págs. 81-92; Diletta TrEgA (2012), I diritti in crisi: tra corti nazionali e Corte Europea di Strasburgo, Milán: Giuffrè. Respecto a Grecia, vid. Irene MARTín CORTÉs e Ignacio TIRAdo MARTí (dirs.) (2015), Grecia: aspectos políticos y jurídico-económicos de la crisis, Madrid: CEPC.

63 Marcos Almeida Cerreda, Claudia Tubertini y Pedro Costa Gonçalves (dirs.) (2015), La racionalización de la organización administrativa local. Las experiencias española, italiana y portuguesa, Madrid: Thomson Reuters-Civitas. Véase también Luis Cosculluela Montaner, Luis Medina Alcoz, María Hernando Rydings y Eloísa Carbonell Porras (coords.) (2012), Crisis económica y reforma del régimen local, Cizur Menor: Aranzadi. 
normas lo son todo salvo genuinamente nacionales. La impronta de las normas generadas en el seno de los organismos internacionales es clara, pero también probablemente — como ya se ha adelantado- la de los Estados que han liderado las políticas para afrontar la crisis.

Otro rasgo que parece ser característico y común a diversos ordenamientos es que el enfoque económico está cambiando las formas de producción normativa y, en particular, está dotando de protagonismo a técnicos no necesariamente versados en cuestiones jurídicas y no caracterizados por ofrecer una visión general de los temas analizando las diversas facetas de la realidad social. Incluso estos técnicos ni siquiera tienen por qué pertenecer a la estructura administrativa, dado que el conocimiento especializado se externaliza y se proporciona por tanto desde fuera de la propia Administración. A nivel internacional son los organismos regulatorios aquellas entidades en las que los «técnicos» presentan una importancia destacada, pero a nivel nacional se reproduce asimismo este esquema ${ }^{64}$.

\section{La jurisprudencia}

Una vez expuestos los interrogantes generales de tipo metodológicocomparado que suscita la crisis económico-financiera en el marco del DAG, se ha de subrayar el interés que presenta para la agenda de investigación el papel de los órganos jurisdiccionales en la interpretación y en la aplicación de las normas surgidas de la crisis. Es pronto aún

64 Cfr. en Italia Giulio Napolitano (2014), La logica del diritto amministrativo, Bolonia: Il Mulino. Desde una perspectiva histórica, pero reivindicando la necesidad de contar con un saber técnico especializado en el seno de la Administración, vid. Guido Melis (2013), "La fuga dall'amministrazione: ascesa e declino dei tecnici nell'amministrazione dell'Italia unita», Rivista trimestrale di diritto pubblico 2, págs. 470-478. En otro contexto, el de la ciencia, José EsTEVE PARDo plantea interrogantes semejantes en varios de sus trabajos. En particular, en El desconcierto del Leviatán (Madrid: Marcial Pons, 2009) alude de manera directa a «la necesaria recuperación por el Derecho de sus espacios propios de decisión y la reinstauración de sus valores y referencias» (págs. 108-113). En este apartado afirmará que «[n]o se trata en modo alguno de una afirmación a favor del derecho, sus operadores, y el estamento de los juristas —que, por supuesto, no se encuentran en ninguna posición supraordenada-, en contra de los científicos y su incuestionable autoridad experta; sencillamente se trata de que sea la propia comunidad política a través de sus representantes y con arreglo al orden jurídico que se ha dado la que tenga el protagonismo decisorio» (pág. 109). Una afirmación de estas características resulta a todas luces pertinente en el tema que nos ocupa en este momento. Con anterioridad, Alejandro NiETo se había manifestado singularmente crítico con la preponderancia de determinados cuerpos técnicos dentro de la Administración - los ingenieros - en su varias veces reeditado y actualizado La organización del desgobierno, Barcelona: Ariel, 1984. Más adelante, en El desgobierno de lo público (Barcelona: Ariel, 2008), se lamentará por la pérdida de competencias técnicas de la Administración debido a la politización de sus entrañas y planteará que en definitiva — por lo anterior - la competencia técnica se externaliza cada vez más (pág. 200). 
para proceder a un análisis con pretensión de exhaustividad, ni siquiera con cierta vocación conclusiva. Sin embargo, sí que existen ya algunas tendencias de interés ${ }^{65}$.

Entre los elementos a analizar se encuentra, en primer lugar, la condescendencia - $\mathrm{O}$ no- de los Tribunales Constitucionales respecto de las normas adoptadas por los Gobiernos amparándose en la pretendida urgencia determinada por la crisis, como es el caso español.

En segundo, y en realidad preeminente, lugar se encuentra la todavía escasa jurisprudencia sobre la sobrevaloración de principios como el de estabilidad presupuestaria frente a otros bienes, valores y objetivos constitucionales, algo sobre lo que han tenido oportunidad de pronunciarse el Tribunal Constitucional italiano ${ }^{66}$, el portugués y con anterioridad el alemán ${ }^{67}$.

En tercer lugar, sería interesante adentrarse en el uso del argumento comparado para articular motivaciones que en realidad responden a un sustrato normativo común supranacional pasado por el tamiz de los operadores jurídicos nacionales. Sin embargo, este argumento comparado, aun teniendo interés ${ }^{68}$, no suele aplicarse y, de hacerse, en muchas

65 Con carácter general me remito a Federico FABBrinI (2014), «The Euro-Crisis and the Courts: Judicial Review and the Political Process in Comparative Perspective», Berkeley Journal of International Law, 32 (1), págs. 64-123.

${ }^{66}$ Cfr., entre otras, la Sentencia núm. 70/2015, de 30 de abril de 2015 y publicada en la Gaceta Oficial el 6 de mayo de 2015. Sobre Portugal me remito al artículo de Ponce (2015).

67 En general, sobre la jurisprudencia constitucional relacionada con los cambios constitucionales y legales derivados de la crisis, vid. por todos Miguel AzPITARTe Sánchez (2014), «Los confines de la democracia y la solidaridad. A propósito de las decisiones del Tribunal Constitucional Federal Alemán de 14 de enero y de 18 de marzo de 2014, que enjuician el marco jurídico-supranacional de las políticas de rescate», Revista Española de Derecho Constitucional, 101, págs. 301-336. Del mismo autor vid. también «En busca del Estado competitivo. Crónica política y legislativa del año 2013», Revista Española de Derecho Constitucional, 100, págs. 191-220 — donde plantea entre otras cuestiones de interés que parece que el nuevo art. $135 \mathrm{CE}$ se utiliza en realidad como título competencial añadido, algo que excede de su posición en el texto constitucional—, así como «El capitalismo sin mercado financiero y sus consecuencias sobre el Estado Constitucional. Crónica política y legislativa en el año 2012», Revista Española de Derecho Constitucional, 97, págs. 151-179. Sobre los argumentos económicos y otro tipo de argumentos en el razonamiento jurídico, en especial tras el reforzamiento constitucional de los primeros tras la reforma del artículo 135 de la Constitución, vid. también Pedro MERCAdo PACHECo (2013), "Calidad de la ley, evaluación de impacto normativo y argumentos económicos», Anales de la Cátedra Francisco Suárez, 47, págs. 85-108.

${ }_{68} \mathrm{Al}$ respecto, partiendo del análisis de un caso concreto, vid. Leonor Moral Soriano (2002), "El punto de vista del comparatista sobre el papel de los precedentes judiciales en Italia», Revista de Derecho Procesal, 3, Lima, págs. 15-29. Véase también Mads Andenas y Duncan FaIRGRIEVE (eds.) (2010), Courts and Comparative Law, Oxford: Oxford University Press; Sabino CASSESE (2010), «Legal Comparison by the Courts», Piélagus, 9; Víctor Ferreres Comella (2001), «Comparative modesty», European Constitutional Law Review, 517; Tania Gropp y Marie-Claire PoNTHOREAu (eds.) (2013), The Use of Foreign Precedents by Constitutional Judges, Oxford: Hart Publishing; Andrea LoLLINI (2012), "El diritto straniero nella giurisprudenza costituzionale: metodi "forte" e "debole" a confronto", Rivista trimestrale di diritto pubblico, 4, págs. 973-1017. 
ocasiones ello ocurre sin mencionarlo de forma explícita ${ }^{69}$. Las indudables ventajas que comporta un diálogo jurisprudencial de este tipo en cuestiones de alcance superior al nacional y en el que otros valores distintos de los estrictamente económicos se encuentran en juego se contraponen a los peligros de quienes critican el argumento comparado por aportar elementos ajenos a las normas adoptadas por aquellos que tienen legalmente atribuida la capacidad de decidir. BRETONNEAU, DAHAN y FAIRGRIEVE, en su reciente análisis del argumento comparado en la jurisprudencia del Consejo de Estado francés, concluyen afirmando que «si la investigación comparada no parecía sino una forma de bricolaje en 2008, se ha convertido desde entonces en un elemento importante de la práctica jurisdiccional» (en el Consejo de Estado). Y ello ha sido debido no solo a la institucionalización de la investigación jurídica comparada, sino sobre todo debido a la «célula» de derecho comparado, que es un servicio específico creado en el seno del Consejo de Estado para elaborar este tipo de trabajo de fondo ${ }^{70}$.

Frente a los riesgos que en cualquier caso comporta un uso no adecuado del derecho comparado alerta Michal BoBEK, que insiste en la necesidad de comprender el contexto en el que surgen y se aplican las normas jurídicas a fin de utilizarlas como elemento comparado. Para ello, la doctrina desempeña un trabajo esencial de intermediación entre la norma de origen y el ordenamiento jurídico de recepción. Además, el juez habrá de justificar por qué elige unas referencias comparadas y no otras, dado que uno u otro ejemplo puede volcar el sentido del pronunciamiento en un sentido o en otro, tal y como con carácter general se expuso más arriba. En esta labor el juez no solo está asistido de la doctrina y de asesores, en su caso, sino que adquieren singular relevancia las redes y asociaciones de interlocutores equivalentes, en las que estas

69 Michael Вовек (2013) propone un análisis del uso del argumento comparado en Comparative Reasoning in European Supreme Courts (Oxford: Oxford University Press). Entiende que es un poderoso instrumento para rellenar lagunas, en especial en los países que siguen la tradición del common law, en los que la argumentación judicial desempeña un papel singularmente relevante. El autor distingue, además, entre argumentos comparados obligatorios y no obligatorios. Los primeros son aquellos exigidos por el ordenamiento jurídico, como resulta en la aplicación del derecho internacional privado, mientras que la mayoría son no obligatorios, sin que ello le reste importancia como criterio interpretativo, como decía, a efectos de integrar lagunas o como «elemento de inspiración». Muy interesante también es la siguiente obra, fruto de entrevistas con jueces de varios Estados para conocer cómo éstos tienen en cuenta normas internacionales y de otros Estados para construir sus decisiones y cómo se están gestando modos comunes de concebir la argumentación judicial utilizando referentes comparados: Elaine MAK (2013), Judicial Decision-Making in a Globalised World: A Comparative Analysis of the Changing Practices of Western Highest Courts, Oxford: Hart Publishing.

${ }^{70}$ Cfr. Aurélie Bretonneau, Samuel Dahan y Duncan Fairgrieve (2015), «L'influence grandissante du droit comparé au Conseil d'État: vers une procédure juridictionnelle innovante», Revue Française de Droit Administratif, 4, págs. 855-860. 
prácticas se ponen en común y se discuten ${ }^{71}$. Cabe señalar, en fin, que en algunos Estados se ha constatado el uso creciente de los referentes comparados en la jurisprudencia, más allá del análisis jurídico-comparado que se realiza en las universidades.

\section{A MODO DE CONCLUSIÓN}

En las líneas anteriores se ha pretendido ofrecer una panorámica del surgimiento y evolución del derecho comparado, apuntando a las estrategias metodológicas que se han ido desarrollando en su seno. Esta disciplina y los análisis que comporta superan con creces los aspectos jurídicos, del mismo modo que lo hacen otros enfoques metodológicos que han adquirido predicamento en los últimos años, como es el caso del análisis económico del derecho. Conceptos como el de contexto o la correcta ubicación de cada cuestión jurídica en su marco cultural constituyen un elemento fundamental de la teoría. La exposición y correcto análisis de dicho contexto es uno de los retos metodológicos más importantes, pero desde luego una de sus máximas utilidades, por cuanto permite contrastar soluciones e indagar en su eventual aplicación en otros lares. Sin embargo, en este mismo aspecto se encuentra su mayor límite, por cuanto los trasplantes legales requieren precisamente de un entorno favorable para su incorporación con éxito.

La singular dificultad de los trasplantes jurídicos en el derecho público ha sido subrayada por algunos autores e incluso se ha llegado a afirmar la imposibilidad de realizar derecho comparado en esta rama del derecho por sus especiales vinculaciones con la historia y la concepción del poder en cada coordenada geográfica. En línea con las dificultades y los límites, se ha de alertar también frente a los eventuales excesos que puede comportar el análisis comparado, por cuanto si bien es cierto que ofrece herramientas adicionales al intérprete, el recurso al argumento comparado como instrumento de interpretación puede implicar que el intérprete se extralimite.

71 Sobre las redes de jueces y su importancia desde una óptica de Derecho Comparado en Europa pueden verse los trabajos de Monica CLAES y Maartje DE VISSER y, en particular, los siguientes: CLAES y DE VISSER (2013), "Courts united? On European judicial networks», en Antoine VAUCHEZ y Bruno DE WITTE (eds.), Lawyering Europe. European law as a transnational social field, Oxford: Hart Publishing, págs. 75-100; DE VISSER y ClaEs (2013), "Judicial networks», en Pierre Larouche y Péter Cserne (eds.) (2013), National legal systems and globalization. New role, continuing relevance, La Haya, TCM Asser Press/Springer, págs. 345-369; CLAES y DE VISSER (2012), «Reflections on the comparative method in European constitutional law», Cambridge: Cambridge University Press, págs. 143-169. 
En las últimas décadas la teoría del derecho comparado en el derecho público ha dejado espacio a aplicaciones concretas en marcos asimismo específicos: el derecho administrativo europeo ${ }^{72}$ y, más recientemente, el derecho administrativo global. Ello ha supuesto un cierto giro metodológico, por cuanto el derecho comparado asume aquí nuevas finalidades. No se trata tanto de mejorar el ordenamiento jurídico de partida, sino de contribuir desde los derechos nacionales a la construcción de categorías jurídicas comunes y de un sistema de garantías satisfactorio. Los desafíos aquí mutan en cierta manera. Adquiere importancia, por ejemplo, la cautela frente al imperio en la construcción del ordenamiento global de determinados ordenamientos jurídicos con sus propias tradiciones, significados y significantes, que pueden no encontrar acomodo fácil en otros Estados destinatarios de ese corpus jurídico. Y es que, en definitiva, la cautela o las cautelas son probablemente el instrumento intelectual más relevante en la comparación jurídica. De modo que el derecho comparado podría definirse como un «derecho de cautelas».

El derecho administrativo global, aun cuando afecta a múltiples áreas del derecho administrativo clásico, tiene un elevado componente económico. En este sentido, presenta interés la agenda de investigación para el derecho comparado que se deriva de las medidas que los Estados han adoptado para afrontar la crisis económica y financiera. En este marco resulta relevante tanto la comparación horizontal como la vertical: cuál es el origen de las normas elaboradas en el espacio global y que luego encuentran aplicación en los Estados, pero también cómo dichos Estados acometen reformas normativas en ejecución de dichos mandatos. La agenda, por lo tanto, es extensa, como lo es el trabajo que queda por delante.

72 Más recientemente y con un enfoque crítico, vid. Massimo BrUTTI (2012), «Per la scienza giuridica europea (riflessioni su un dibattito in corso)», Rivista trimestrale di diritto pubblico, 4, págs. 905-932. En concreto, respecto del uso del derecho comparado en las agendas de investigación del derecho administrativo europeo y, se sobreentiende, del derecho administrativo global, considera que existe una actividad de «valoración y direccionamiento» [ «valutazione»e «indirizzo»] en el uso de referentes y alerta frente a la inclusión de una "política del Derecho» que fije los objetivos que han de ser perseguidos en la actividad científica (pág. 919). El autor propone frente a esto dejar de lado el método axiomático para fortalecer el uso del método tópico, basado en el debate y la persuasión. 
